\title{
Waiting time to radiotherapy as a prognostic factor for glioblastoma patients in a scenario of medical disparities
}

\author{
Tempo de espera para a radioterapia como um fator prognóstico em pacientes com \\ glioblastoma em um cenário de disparidades médicas
}

Luiz Victor Maia Loureiro ${ }^{1,2}$, Luciola de Barros Pontes ${ }^{3}$, Donato Callegaro-Filho ${ }^{1}$, Ludmila de Oliveira Koch?', Eduardo Weltman ${ }^{1,4}$, Elivane da Silva Victor ${ }^{1}$, Adrialdo José Santos², Lia Raquel Rodrigues Borges², Roberto Araújo Segreto², Suzana Maria Fleury Malheiros ${ }^{1,2}$

\begin{abstract}
Objective: To evaluate the effect of waiting time (WT) to radiotherapy (RT) on overall survival (OS) of glioblastoma (GBM) patients as a reliable prognostic variable in Brazil, a scenario of medical disparities. Method: Retrospective study of 115 GBM patients from two different health-care institutions (one public and one private) in Brazil who underwent post-operative RT. Results: Median WT to RT was 6 weeks (range, 1.3-17.6). The median OS for WT $\leq 6$ weeks was 13.5 months $(95 \% \mathrm{Cl}, 9.1-17.9)$ and for WT $>6$ weeks was 14.2 months (95\% Cl, 11.2-17.2) (HR 1.165, 95\% Cl 0.770-1.762; $p=0.470)$. In the multivariate analysis, the variables associated with survival were KPS ( $p<0.001)$, extent of resection $(p=0.009)$ and the adjuvant treatment $(p=0.001)$. The KPS interacted with WT to RT (HR 0.128, 95\%Cl 0.034-0.476; $p=0.002$ ), showing that the benefit of KPS on OS depends on the WT to RT. Conclusion: No prognostic impact of WT to RT could be detected on the OS. Although there are no data to ensure that delays to RT are tolerable, we may reassure patients that the time-length to initiate treatment does not seem to influence the control of the disease, particularly in face of other prognostic factors.
\end{abstract}

Keywords: glioblastoma, radiotherapy, waiting time, delay, prognosis, survival.

\section{RESUMO}

Objetivo: Avaliar o efeito do tempo de espera (TE) até radioterapia na sobrevida global de pacientes com glioblastoma como um fator prognóstico confiável. Método: Estudo retrospectivo de 115 pacientes com glioblastoma, que foram submetidos à radioterapia pósoperatória, em dois serviços diferentes no Brasil (um público e outro privado). Resultados: Mediana de TE para radioterapia foi de 6 semanas (variação, 1,3-17,6). A mediana de sobrevida para TE $\leq 6$ semanas foi de 13,5 meses (IC95\%, 9,1-17,9) e para TE > 6 semanas foi de 14,2 meses (IC95\%, 11,2-17,2) (HR 1,165, 0,770-1,762; $p=0,470)$. Na análise multivariada, as variáveis associadas à sobrevida foram perfomance status $(p<0,001)$, extensão da ressecção $(p=0,009)$ e tratamento adjuvante $(p=0,001)$. Conclusão: Não se observou impacto prognóstico para TE até a radioterapia na sobrevida. Diante de outros fatores prognósticos, é possível assegurar de que o espaço de tempo até a radioterapia não parece influenciar o controle da doença.

Palavras-chave: glioblastoma, radioterapia, tempo de espera, atraso, prognóstico, sobrevida.

The investigation of the impact of delaying radiotherapy (RT) on the outcomes of various tumors - particularly breast and head-and-neck - has generated no clear results. Nevertheless, there is considerable evidence to support that delay of RT may have an adverse effect on patients' outcomes ${ }^{1,2,3}$.
Glioblastoma (GBM) patients have been the subject of many clinical investigations aiming to determine the effects of waiting time (WT) for initiation of $\mathrm{RT}^{4,5,6,7,7,9,10,11,12,13,14,15,16}$. Much of the interest in seeking a presumable negative impact of the delay for this kind of tumor is based on its

\footnotetext{
${ }^{1}$ Hospital Israelita Albert Einstein, Sao Paulo SP, Brazil;

${ }^{2}$ Universidade Federal de São Paulo, Escola Paulista de Medicina, Sao Paulo SP, Brazil;

${ }^{3}$ Hospital do Coração, Departamento de Oncologia, Sao Paulo SP, Brazil;

${ }^{4} U$ niversidade de São Paulo, Faculdade de Medicina, Sao Paulo SP, Brazil.

Correspondence: Luiz Victor Maia Loureiro; Hospital Israelita Albert Einstein, Serviço de Oncologia e Hematologia; Av. Albert Einstein, 627 / bloco A - $3^{\circ}$ subsolo; 05652-900 São Paulo SP, Brasil; E-mail: Ivmaia@gmail.com

Conflict of interest: There is no conflict of interest to declare.

Support: Instituto UNIEMP, Instituto Israelita de Ensino e Pesquisa Albert Einstein.

Received 11 April 2014; Received in final form 19 September 2014; Accepted 10 October 2014.
} 
median overall survival (OS) that rarely exceeds 14 months ${ }^{17}$. So far, available reports are still controversial, although most of the data show no evidence to justify delaying RT beyond 6 weeks $^{18}$.

Due to multiple factors, Brazil faces a shortage of RT resources and, according to the most recent data, only $65.9 \%$ of the RT demand is met. Nationwide and regardless of tumor type, the mean WT to RT is 113.4 days (almost 4 months) and, barely $15 \%$ of the patients initiate RT before 4 weeks following diagnosis ${ }^{19,20}$. This unfortunate reality and the well-known Brazilian medical disparities have provided the perfect scenario to evaluate a cohort of GBM patients regarding the effect of RT delay on survival. Therefore, this study aimed to evaluate the impact of WT to RT as a reliable prognostic variable in 115 GBM patients from two different health-care institutions in the country.

\section{METHOD}

We conducted a retrospective study of adult patients ( $\geq 18$ years old) who had a newly diagnosed GBM according to World Health Organization classification (WHO, 2007) ${ }^{21}$ and were treated with RT after surgery, between January 2003 and December 2011, from two Brazilian hospital databases: Hospital Israelita Albert Einstein (HIAE), a private-practice service, and Hospital São Paulo - Universidade Federal de São Paulo (HSP-UNIFESP), a public healthcare center.

The medical records of 132 patients were reviewed in order to obtain relevant data: gender, age at diagnosis, Karnofsky Performance Status (KPS), date of first symptom, date of death, date and extent of neurosurgery based on postoperative CT or MRI (within the first 48 hours), and characteristics of RT and chemotherapy. We did not investigate the causes of delay in RT. We excluded 17 patients due to missing data: 3 had no information on the extent of resection, 8 had no information about the adjuvant treatment and, 6 because no starting date of RT was reported. The remaining 115 patients (76 from HSP-UNIFESP and 39 from HIAE) formed our study cohort.

Patients underwent neurosurgical procedure aiming for maximal safe resection whenever possible. All analyzed subjects underwent 3D localized external beam RT using treatment planning systems based on the contrast-enhancing lesion shown on pre-operative contrast-enhanced TC and/ or T2/FLAIR sequence MRI. For the purpose of this study, we recorded only the maximum dose actually delivered to the tumor bed at the time of the initial RT, typically 60 Gy in 30 fractions.

At HSP-UNIFESP, before 2009, the patients received Carmustine (BCNU) $200 \mathrm{mg} / \mathrm{m}^{2}$ at 6 weeks intervals starting 6 weeks after RT. Since 2009, Temozolomide (TMZ) became available and patients could be treated according to the EORTC-NCIC protocol ${ }^{22}$. At HIAE, all patients were treated according to EORTC-NCIC protocol ${ }^{22}$. The patients who underwent concomitant and adjuvant TMZ were categorized as "RT concurrent with chemotherapy"; those who received BCNU were defined as "RT and sequencing chemotherapy".

The ethics review board of both institutions approved this study.

\section{Statistical analysis}

Data were described using absolute and relative frequencies for categorical data. Quantitative data were described using median and range, due to skewness. OS was calculated from time of diagnosis until death or last follow up (cut-off date October 17, 2012).

The waiting time between first symptoms and neurosurgery (WT to NS) was calculated using the estimated date of first symptoms to the day of the neurosurgical intervention (biopsy or surgical resection) and was categorized based on its median. The WT to RT was calculated in weeks between the date of the first neurosurgery and the starting date of RT. We categorized WT to RT based on its median into two groups: RT delay $\leq 6$ weeks $(\mathrm{WT} \leq 6)$ and RT delay $>6$ weeks $(\mathrm{WT}>6$ ). Data from the groups were compared by using Pearson's Chi-square or Fisher's test for categorical data and Mann-Whitney $U$-test for quantitative variables. A p-value of $<0.05$ was considered significant.

Survival curves were constructed according to the Kaplan-Meier method and compared between groups using log-rank test to explore relationships between well-recognized prognostic factors (age, KPS, extent of resection, adjuvant treatment) and survival in the univariate analysis. Data from two diverse institutions were evaluated and we observed a significant association between WT to RT and institution. In order to avoid multicolinearity, only the WT to RT was explored as a prognostic factor.

A conditional stepwise proportional hazard analysis (Coxregression model) was used to identify independent predictors of survival. The variables that achieved a $\mathrm{p}$-value $<0.1$ in the univariate analysis were included in the multivariate model. The WT to RT variable was retained in the model because it is the object of the study, although not significant in the univariate analysis. In addition, we explored the interactions among WT to RT and other variables, and the multivariate model was adjusted to include only significant interactions.

The statistical analysis was performed using the statistical softwares R (R Core Team (2012). R: A language and environment for statistical computing. R Foundation for Statistical Computing, Vienna, Austria. ISBN 3-900051-07-0, URL http://www.R-project.org/) and SPSS (SPSS Inc. Released 2008. SPSS Statistics for Windows, Version 17.0. Chicago: SPSS Inc.). 


\section{RESULTS}

For the entire cohort, the median age was 57 years (range, 18-83). There were 44 females and 71 males (ratio 1:1.6). The median intervals were: WT to NS 6.7 weeks (range, 0.14-1435) and WT to RT 6 weeks (range, 1.3-17.6). Median final RT dose was 60 Gy (range, 10-66). Median follow-up time was 12.9 months (range, 1.1-58) and estimated OS was 14.1 months (95\%CI, 11.6-16.6).

The median interval for WT $\leq 6$ group was 4.1 weeks (range, 1.3-6) and 8.6 weeks (range, 6.1-17.6) for the WT $>6$ group. Table 1 shows patients' demographics, clinical and treatment characteristics as a function of the WT to RT interval.

We did not observe a deleterious effect of longer WT to RT on survival, as shown in Figure 1. The median OS for $\mathrm{WT} \leq 6$ was 13.5 months $(95 \% \mathrm{CI}, 9.1-17.9)$ and for $\mathrm{WT}>6$ was 14.2 months (95\%CI, 11.2-17.2) (HR 1.165, 95\%CI 0.770-1.762; $\mathrm{p}=0.470$ ). We observed a significantly better OS for age $<50$ years, KPS $\geq 70 \%$, final total RT dose $\geq 60$ Gy and adjuvant treatment including any chemotherapy (Table 2).

We explored the impact of clinical characteristics and adjuvant treatment on OS using a Cox regression model (Table 3). The only significant clinical variable associated with survival was KPS $(\mathrm{p}<0.001)$. Regarding treatment characteristics, the extent of resection $(p=0.009)$ and the adjuvant treatment $(\mathrm{p}=0.001)$ had also an association with OS.

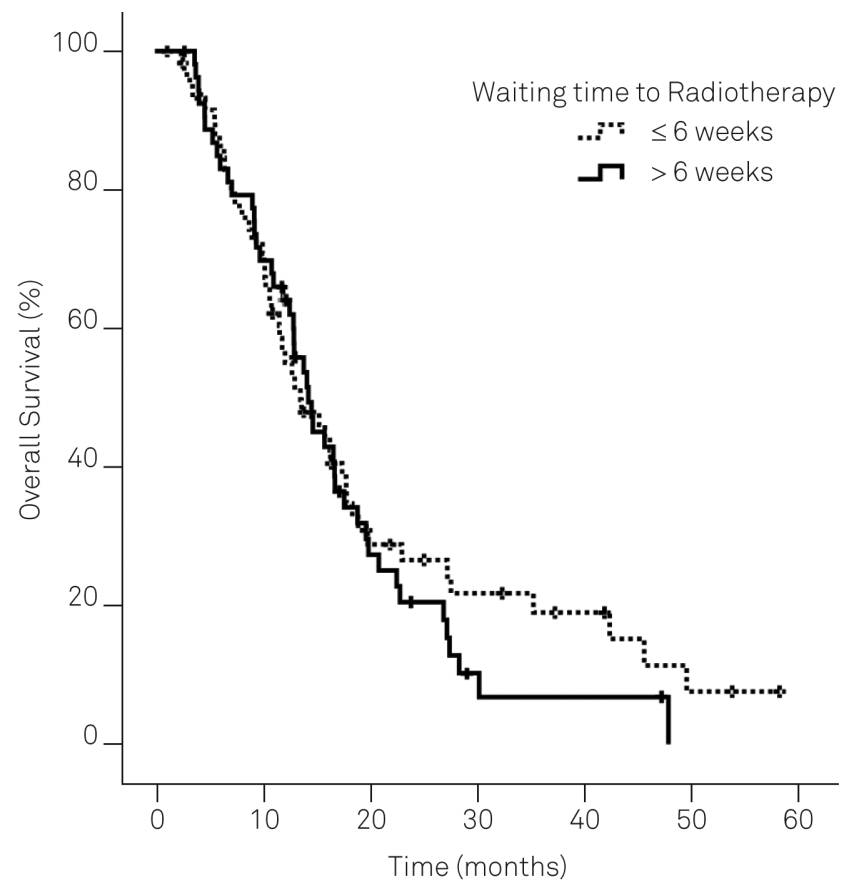

Figure 1. Overall survival according to waiting time from neurosurgery to radiotherapy for glioblastoma patients $(p=0.470)$.

We also evaluated the potential interactions between patient's characteristics and WT to RT. The only variable that interacted with WT to RT was KPS. Figure 2 shows that the effect of KPS on OS depends on the WT to RT.

Table 1. Demographics, clinical and treatment characteristics of patients according to the WT to RT interval.

\begin{tabular}{|c|c|c|c|}
\hline & $W T \leq 6$ & WT $>6$ & \\
\hline & $61(53 \%)$ & $54(47 \%)$ & 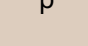 \\
\hline Gender & & & 0.159 \\
\hline Male & 34 (55.7\%) & $37(68.5 \%)$ & \\
\hline Age (years) & & & 0.071 \\
\hline$<50$ & $14(23.0 \%)$ & $21(38.9 \%)$ & \\
\hline$\geq 50$ & $47(77.0 \%)$ & $33(61.1 \%)$ & \\
\hline KPS (\%) & & & 0.423 \\
\hline$<70$ & $11(23.4 \%)$ & $9(17.0 \%)$ & \\
\hline$\geq 70$ & $36(76.6 \%)$ & $44(83.0 \%)$ & \\
\hline Neurosurgery (extent of resection) & & & 0.115 \\
\hline Biopsy & $8(13.1 \%)$ & $3(5.6 \%)$ & \\
\hline Partial & $20(32.8 \%)$ & $27(50.0 \%)$ & \\
\hline Gross-total & $33(54.1 \%)$ & $24(44.4 \%)$ & \\
\hline WT to NS & & & 0.021 \\
\hline$\leq 6.7$ weeks & $33(61.1 \%)$ & $21(38.9 \%)$ & \\
\hline$>6.7$ weeks & $21(38.9 \%)$ & $33(61.1 \%)$ & \\
\hline Final total RT dose (Gy) & & & 0.050 \\
\hline$<60$ & $15(26.3 \%)$ & $23(44.2 \%)$ & \\
\hline$\geq 60$ & $42(73.7 \%)$ & $29(55.8 \%)$ & \\
\hline Adjuvant treatment & & & 0.004 \\
\hline RT Only & $13(21.3 \%)$ & $15(27.8 \%)$ & \\
\hline RT and sequencing chemotherapy & $11(18.0 \%)$ & $22(40.7 \%)$ & \\
\hline RT concurrent with chemotherapy & $37(60.7 \%)$ & $17(31.5 \%)$ & \\
\hline
\end{tabular}

WT: Waiting time; RT: Radiotherapy; KPS: Karnofsky performance status; WT to NS: Waiting time between first symptoms and neurosurgery. 
Table 2. Overall survival according to patients' characteristics.

\begin{tabular}{|c|c|c|c|c|}
\hline & Median survival time in months $(95 \% \mathrm{Cl})$ & HR & $(95 \% \mathrm{Cl})$ & $p$ \\
\hline Age (years) & & & & 0.032 \\
\hline$<50$ & $18.8(15.0-22.6)$ & & & \\
\hline$\geq 50$ & $12.5(10.1-14.9)$ & 1.637 & $(1.042-2.571)$ & \\
\hline KPS (\%) & & & & $<0.001$ \\
\hline$<70$ & $9.0(5.1-12.9)$ & & & \\
\hline$\geq 70$ & $15.8(13.3-18.2)$ & 0.377 & $(0.220-0.648)$ & \\
\hline Neurosurgery (extent of resection) & & & & 0.096 \\
\hline Biopsy & $11.5(9.7-13.3)$ & & & \\
\hline Partial & $15.7(11.3-20.1)$ & 0.613 & $(0.297-1.264)$ & \\
\hline Gross-total & $14.1(11.8-16.4)$ & 0.464 & $(0.224-0.962)$ & \\
\hline WT to NS & & & & 0.295 \\
\hline$\leq 6.7$ weeks & $15.7(12.7-18.8)$ & & & \\
\hline$>6.7$ weeks & $12.9(10.0-15.7)$ & 1.252 & $(0.822-1.908)$ & \\
\hline Final total RT dose (Gy) & & & & 0.042 \\
\hline$<60$ & $11.0(8.2-13.7)$ & & & \\
\hline$\geq 60$ & $16.2(13.5-19.0)$ & 0.641 & $(0.418-0.985)$ & \\
\hline Adjuvant Treatment & & & & $<0.001$ \\
\hline RT Only & $8.1(5.2-11.0)$ & & & \\
\hline RT and sequencing chemotherapy & $15.8(13.8-17.7)$ & 0.282 & $(0.163-0.487)$ & \\
\hline RT concurrent with chemotherapy & $17.7(15.2-20.2)$ & 0.231 & $(0.136-0.394)$ & \\
\hline
\end{tabular}

WT: Waiting time; RT: Radiotherapy; KPS: Karnofsky performance status; WT to NS: Waiting time between first symptoms and neurosurgery; HR: Hazard ratio; Cl: confidence interval.

\section{DISCUSSION}

In this study of 115 GBM Brazilian patients, delaying RT longer than 6 weeks did not affect the OS and may not be credited as a reliable prognostic factor (HR 1.323, 95\%CI 0.731-2.393; $\mathrm{p}=0.355)$. The problem of delaying RT in GBM treatment has been debated more extensively because of the fast-growing nature of this tumor ${ }^{13}$ and its ability to invade surrounding tissues, making tumor control much more difficult over time $e^{23,24}$. To date, data published on this theme are considered controversial, partially because prior studies presented diverse methodologies and patients with different characteristics ${ }^{4,5,6,7,7,8,9,10,11,12,13,16,18}$.

In line with our data, previous reports failed in detecting any disadvantage in delaying RT. In 2000, Do et al. ${ }^{4}$ in the first published attempt to address the issue, reported

Table 3. Multivariate analysis.

\begin{tabular}{|c|c|c|c|}
\hline & $\mathrm{HR}$ & $(95 \% \mathrm{Cl})$ & $\mathrm{p}$ \\
\hline WT to RT & & & 0.355 \\
\hline$\leq 6$ weeks & 1 & & \\
\hline$>6$ weeks & 1.323 & $(0.731-2.393)$ & \\
\hline Age (years) & & & 0.837 \\
\hline$<50$ & 1 & & \\
\hline$\geq 50$ & 0.939 & $(0.518-1.705)$ & \\
\hline KPS (\%) & & & $<0.001$ \\
\hline$\leq 70$ & 1 & & \\
\hline$<70$ & 6.794 & $(2.799-16.49)$ & \\
\hline \multicolumn{4}{|l|}{ Neurosurgery (extent of resection)* } \\
\hline Gross-total & 1 & & \\
\hline Partial & 1.174 & $(0.712-1.937)$ & 0.530 \\
\hline Biopsy & 4.382 & $(1.703-11.278)$ & 0.002 \\
\hline \multicolumn{4}{|l|}{ Final total dose of RT (Gy) } \\
\hline$\geq 60$ & 1 & & \\
\hline$<60$ & 1.176 & $(0.708-1.954)$ & 0.531 \\
\hline \multicolumn{4}{|l|}{ Adjuvant treatment ${ }^{\dagger}$} \\
\hline RT concurrent with chemotherapy & 1 & & \\
\hline RT and sequencing chemotherapy & 1.184 & $(0.651-2.154)$ & 0.580 \\
\hline RT Only & 3.259 & $(1.713-6.202)$ & $<0.001$ \\
\hline
\end{tabular}




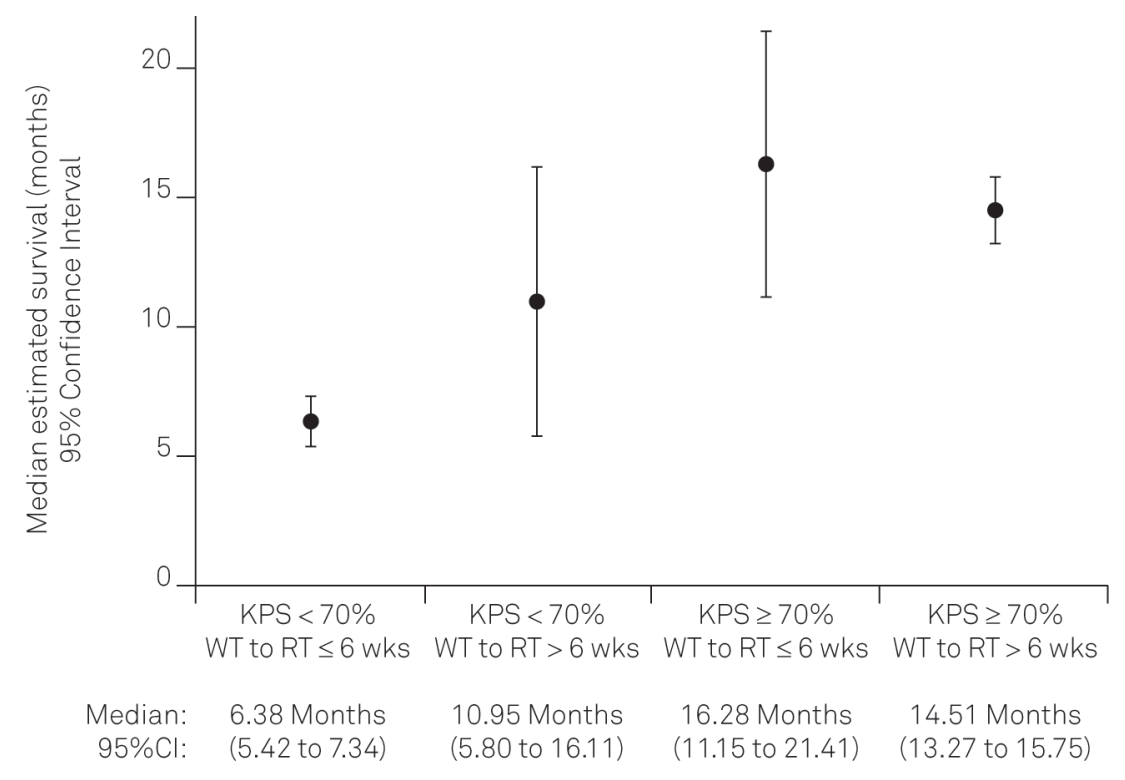

WT: Waiting time; RT: Radiotherapy; KPS: Karnofsky performance status.

Figure 2. Median estimated survival time according to WT to RT and KPS.

no detrimental impact on survival when longer intervals between neurosurgery and RT occurred (HR 1.00, 95\%CI $0.99-1.02 ; \mathrm{p}=0.09$ ). The main limitation of that study was the inclusion in the same cohort of grade 3 and grade 4 gliomas, which are currently known to present different behaviors. Other authors ${ }^{6,8,9,10,12}$, already working in the era of TMZ concomitant with RT, support the result of no significant effect of longer WT to RT on OS in GBM patients. Likewise, using a huge cohort extracted from patients enrolled in the Radiation Therapy Oncology Group (RTOG) protocols, and accounting for close to 3,000 GBM patients, Blumenthal et al. ${ }^{7}$ found no reduction in survival associated with RT delay, within a temporal limit of 6 weeks. Remarkably, median survival was significantly greater for those with the longest WT to RT ( $>4$ weeks) than the group presenting a shorter WT to RT $(\leq 2$ weeks) $(\mathrm{p}<0.001)$. Some authors ${ }^{14,15,16}$ reported comparable unexpected results when patients submitted to a longer WT to RT had also a longer survival. Similarly, we observed the same tendency for better survival for WT $>6$ (median 14.2 months), although not significant $(\mathrm{p}=0.470)$. These patients $(\mathrm{WT}>6)$ had no remarkable advantage regarding age, KPS and, treatment characteristics if compared to the WT $\leq 6$ group. No clear radiobiological mechanisms can be proposed to explain such phenomenon, although physician selection bias of poor performance patients has already been pointed out as an alternative reason ${ }^{7}$. Some authors corroborate this hypothesis suggesting that better performing patients wait longer to $\mathrm{RT}^{5,9,16,18}$. In our cohort, the only clinical variable that interacted with WT to RT was KPS (HR 0.128, 95\%CI 0.034-0.476; p = 0.002), showing that the benefit of KPS on OS depends on the WT to RT. In fact, as depicted in Figure 2, when patients with KPS $<70 \%$ were submitted to RT in $\leq 6$ weeks they showed the worst OS (6.4 months; range, 5.4-7.3). This is a particular potential bias for some retrospective studies published so far, since poor prognosis patients seem to be first in line for treatment.

Three studies reached conclusions opposing our data. Irwin et $a .^{5}$ were the first to report a negative impact of the delay in RT for GBM patients. The study reported a mean WT to RT of 5.01 weeks and, each additional week of delay increases the risk of death by $8.9 \%$ (HR 1.089, 95\% CI 1.020-1.161; $\mathrm{p}=0.010$ ). The major limitations of the study were the inclusion of two pathology subtypes (grade 3 and 4 gliomas) and the great variability of RT dose used. Only $30.8 \%$ of the patients received a final dose of $\geq 60$ Gy and some patients had their RT dose chosen based upon the performance status. In addition, in their multivariate analysis, the RT dose was found to positively influence survival. Our patients were more homogeneous since the final total RT dose between the groups was similar $(p=0.05)$, and all subjects underwent the same RT technique over the period, targeting a final dose of 60 Gy. As for Valduvieco et al. ${ }^{11}$ study, 107 GBM patients submitted to a complete surgical resection were analyzed and showed WT to RT $\leq 6$ weeks as an independent survival predictor (HR 0.42, 95\%CI 0.06-0.96; $\mathrm{p}=0.043$ ). However, some limitations must be pointed out: first, the WT to RT cut-off of 6 weeks was chosen based on historical data and not on its median, causing an imbalance between the groups; second, the restricted inclusion criterion of completed resected patients may limit the generalizability of their results; third, significantly more patients $(86 \%$, 
$p=0.0014)$ in the RT delay $\leq 6$ weeks subgroup received some kind of chemotherapy, creating a potential bias since the use of chemotherapy (TMZ or nitrosureas) was associated with longer survival in the multivariate analysis. In our study, we decided to use the TMZ concomitant with RT as the reference value in the multivariate analysis, aiming to minimize the interpretation bias and we did not detect any advantage when comparing TMZ to the use of sequential chemotherapy (BCNU). In addition, the use of adjuvant chemotherapy (BCNU or TMZ) was equivalently allocated between our subgroups (WT $\leq 6$ weeks $78 \%$ x WT $>6$ weeks $71 \%$ ). Lastly, in an impressive cohort of $345 \mathrm{TMZ}$ treated GBM patients, Spratt et al. ${ }^{16}$ demonstrated a detrimental effect of delaying RT greater than 6 weeks (HR 3.76, 95\%CI 1.01-14.57; p = 0.05) for a subset of patients with known O6-methylguanine DNA methyltransferase (MGMT) status; although only $45.8 \%$ of their cohort had MGMT status. No detrimental impact on OS was found ( $\mathrm{HR} 1.68,95 \% \mathrm{CI}$ 0.94-3.06; $\mathrm{p}=0.08$ ) when the entire cohort was analyzed, including unknown MGMT status patients.

Although we could not retrieve the causes of delaying RT, there is an interest in understanding what would justify the WTs to RT since it is well known that the delay may causes distress and sometimes impact the quality of life due to persisting symptoms ${ }^{24}$. Many authors argue that the inevitable reason for increasing WTs is the failure to reconcile RT to its demand, creating a continuous imbalance ${ }^{1,2,3}$. Even developed countries face this problem ${ }^{25,26,27,28,29}$, which may be even more profound in primarily government funded health care systems. In Brazil, despite recent government efforts ${ }^{19}$, the scenario is still worrisome and the growing demand for RT has created an inefficient system where only $65.9 \%$ of the demand is met and long WTs are commonplace with a median WT to RT of 113.4 days (almost 4 months) ${ }^{19,20}$, regardless of tumor type. Indeed, our data reveals a median interval for $\mathrm{WT}>6$ group of 8.6 weeks, but in this subset, WT as long as 17.6 weeks could be found. Another relevant aspect of the situation is the lengthy admission process into the health care system, which may be reflected in the WT to NS (median of 6.7 weeks). Most patients (61.1\%) who waited longer for neurosurgery ( $>6.7$ weeks) also had a longer WT to RT ( $>6$ weeks) $(\mathrm{p}=0.021)$. This may be seen as an indication of failure to obtain adequate care when early symptoms first occur. We are aware though that the date of the first symptom may be a source of error, which may add bias to these results.

Our study has some limitations. First, its retrospective nature may subject the study to common drawbacks such as patient uncontrolled selection bias and missing data. Thus, our results may not apply in other temporal and spatial contexts. To minimize the selection bias we controlled our analysis considering well-known prognostic factors. It should be noted that a randomized controlled trial to finally elucidate this important debate might not be possible due to ethical issues ${ }^{1,2,3,18}$. Second, we included patients from two diverse health-care institutions and the WT to RT was significantly related to the institution. However, we must emphasize that to avoid multicolinearity, only the WT to RT was explored as a prognostic factor. Additionally, we reported before that the medical assistance scenario was not an independent predictor of survival ${ }^{30}$ and, by electing patients from two diverse healthcare settings, we aimed to reflect the Brazilian reality. Third, we included only patients submitted to RT at some point of their treatment. Lastly, the long time period of the study may have affected the final results due to the diverse adjuvant treatment approaches. To minimize this potential bias, as stated earlier, we decided to use the RT concurrent with chemotherapy as the reference treatment in the multivariate analysis and observed that no advantage was found when comparing this regimen to the use of sequencing chemotherapy (BCNU) (HR 1.184, 95\%CI $0.651-2.154 ; \mathrm{p}=0.580$ ). Therefore, it is unlikely that the addition of TMZ in the treatment arsenal caused any bias to the outcome of our sample.

Our results echo much of the previous published data and no prognostic impact of WT to RT could be detected on the survival of GBM patients. Although there are no data to ensure that delays to RT are tolerable, we may reassure patients that the control of the disease does not seem to be influenced by the time-length to initiate treatment, particularly when we consider the power of other prognostic factors. In any case, we should not lose sight of the increasing imbalance between the RT demand and supply and the imperative need of a carefully planned strategy by the healthcare system to handle this challenge.

\section{Acknowledgments}

We would like to thank all the neurosurgeons at the participating hospitals: Guilherme Carvalhal Ribas, Jorge Roberto Pagura, Luiz Daniel Marques Neves Cetl, Manoel de Paiva Neto, Marcos Augusto Stávale Joaquim, Miguel Montes Canteras, Oreste Paulo Lanzoni, Reynaldo André Brandt and Wanderley Cerqueira de Lima.

\section{References}

1. Chen Z, King W, Pearcey R, Kerba M, Mackillop WJ. The relationship between waiting time for radiotherapy and clinical outcomes: a systematic review of the literature. Radiother Oncol. 2008;87(1):3-16. http://dx.doi.org/10.1016/j.radonc.2007.11.016
2. Huang J, Barbera L, Brouwers M, Browman G, Mackillop W. Does delay in starting treatment affect the outcomes of radiotherapy? A systematic review. J Clin Oncol. 2003;21(3):555-63. http://dx.doi.org/ 10.1200/JCO.2003.04.171 
3. Mackillop, W J. Killing time: the consequences of delays in radiotherapy. Radiother Oncol. 2007;84(1):1-4. http://dx.doi.org/ 10.1016/j.radonc.2007.05.006

4. Do V, Gebski V, Barton M. The effect of waiting for radiotherapy for grade III/IV gliomas. Radiother Oncol. 2000;57(2):131-6. http://dx.doi. org/10.1016/S0167-8140(00)00257-7

5. Irwin C, Hunn M, Purdie G, Hamilton D. Delay in radiotherapy shortens survival in patients with high grade glioma. J Neurooncol. 2007;85(3):339-43. http://dx.doi.org/10.1007/s11060-007-9426-z

6. Lopez S, Calugaru V, Lamproglou I, Boskos C, Taillibert S, Simon J-M et al. [The effect of waiting list for radiotherapy for glioblastoma]. Cancer Radiother. 2008;12(5):497-9. French. http://dx.doi.org/ 10.1016/j.canrad.2008.03.006

7. Blumenthal DT, Won M, Mehta MP, Curran WJ, Souhami L, Michalski $\mathrm{JM}$ et al. Short delay in initiation of radiotherapy may not affect outcome of patients with glioblastoma: a secondary analysis from the radiation therapy oncology group database. J Clin Oncol. 2009;27 (5):733-9. http://dx.doi.org/10.1200/JC0.2008.18.9035

8. Noël G, Quetin P, Heymann S, Karamanoukian D, Schott R. [Diagnostic and treatment delays do not modify the treatment outcome of patients with multiform glioblastoma]. Cancer Radiother. 2009;13(1):17-23. French. http://dx.doi.org/10.1016/j.canrad.2008. 10.002

9. Noel G, Huchet A, Feuvret L, Maire JP, Verrelle P, Le Rhun E et al. Waiting times before initiation of radiotherapy might not affect outcomes for patients with glioblastoma: a French retrospective analysis of patients treated in the era of concomitant temozolomide and radiotherapy. J Neurooncol. 2012;109(1):167-75. http://dx.doi. org/10.1007/s11060-012-0883-7

10. Graus F, Bruna J, Pardo J, Escudero D, Vilas D, Barceló I et al. Patterns of care and outcome for patients with glioblastoma diagonsed during 2008-2010 in Spain. Neuro Oncol. 2013;15(6):797-805. http://dx.doi. org/10.1093/neuonc/not013

11. Valduvieco I, Verger E, Bruna J, Caral L, Pujol T, Ribalta T et al. Impact of radiotherapy delay on survival in glioblastoma. Clin Transl Oncol. 2013;15(4):278-82. http://dx.doi.org/10.1007/s12094-012-0916-x

12. Lai R, Hershman D, Doan T, Neugut A. The timing of cranial radiation in elderly patients with newly diagnosed glioblastoma multiforme. Neuro-oncology. 2010;12(2):190-8.

13. Burnet NG, Jena R, Jefferies SJ, Stenning SP, Kirkby NF. Mathematical modelling of survival of glioblastoma patients suggests a role for radiotherapy dose escalation and predicts poorer outcome after delay to start treatment. Clin Oncol (R Coll Radiol). 2006;18(2):93-103. http://dx.doi.org/10.1016/j.clon.2005.08.017

14. Abacioglu M, Akgun Z, Ucuncu Kefeli A, Atasoy BM, Caglar HB. Effect of time interval between surgical resection and radiotherapy on survival of patients with glioblastoma. Int J Radiat Oncol Biol Phys. 2009;75(3 Suppl):S229. http://dx.doi.org/10.1016/j.ijrobp.2009.07.528

15. Tezcanli EK, Ucuncu A, Sarihan S, Aksu A, Eroglu C, Alco G et al. Does the timing of radiotherapy impact survival of glioblastoma multiforme patients? Int J Radiat Oncol Biol Phys. 2011;81(2 Suppl):S2767. http://dx.doi.org/10.1016/j.ijrobp.2011.06.478

16. Spratt DE, Folkert M, Zumsteq ZS, Chan TA, Beal K, Gutin PH et al. Temporal relationship of post-operative radiotherapy with temozolomide and oncologic outcome for glioblastoma. J Neurooncol. 2014;116(2):357-63. http://dx.doi.org/10.1007/s11060-013-1302-4

17. Stupp R, Hegi ME, Mason WP, Bent MJ, Taphoorn MJ, Janzer RC et al. Effects of radiotherapy with concomitant and adjuvant temozolomide versus radiotherapy alone on survival in glioblastoma in a randomised phase III study: 5-year analysis of the EORTC-NCIC trial. Lancet Oncol. 2009;10(5):459-66. http://dx.doi.org/10.1016/S14702045(09)70025-7

18. Lawrence YR, Blumenthal DT, Matceyevsky D, Kanner AA, Bokstein F, Corn BW. Delayed initiation of radiotherapy for glioblastoma: how important is it to push to the front (or the back) of the line? J Neurooncol. 2011;105(1)1-7. http://dx.doi.org/10.1007/s11060-0110589-2

19. Ferrigno R. Panorama da radioterapia no Brasil. São Paulo: Sociedade Brasileira de Radioterapia; 2013 [cited 2014 Jan 10]. Disponivel em: http://www.sbradioterapia.com.br/pdfs/panorama2013. pdf

20. Tribunal de Contas da União. Secretaria de Fiscalização e Avaliação de Programas de Governo. Relatório de auditoria operacional na politica Nacional de Atenção Oncológica. Brasília: Tribunal de Contas da União; 2010 [cited 2014 jan 10]. Disponível em: http://portal2.tcu.gov. $\mathrm{br} /$ portal/page/portal/TCU/comunidades/programas_governo/areas_ atuacao/saude/Oncologia\%20-\%20relat\%C3\%B3rio\%20-\%20vers\% C3\%A3०\%20final.pdf

21. Rousseau A, Mokhtari K, Duyckaerts C. The 2007 WHO classification of tumors of the central nervous system - what has changed? Curr Opin Neurol. 2008;21(6):720-7. http://dx.doi.org/10.1097/WCO. Ob013e328312c3a7

22. Stupp R, Mason WP, Weller M, Fisher B, Taphoorn MJ, Belanger K et al. Radiotherapy plus concomitant and adjuvant temozolomide for glioblastoma. N.Engl J Med. 2005;352(10):987-96. http://dx.doi.org/ 10.1056/NEJMoa043330

23. Pirzkall A, McGue C, Saraswathy S, Cha S, Liu R, Vandenberq S et al. Tumor regrowth between surgery and initiation of adjuvant therapy in patients with newly diagnosed glioblastoma. Neuro Oncol. 2009;11 (6):842-52. http://dx.doi.org/10.1215/15228517-2009-005

24. Mackillop WJ, Bates JH, O'Sullivan B, Withers HR. The effect of delay in treatment on local control by radiotherapy. Int $\mathrm{J}$ Radiat.Oncol Biol.Phys. 1996;34(1):243-50. http://dx.doi.org/10.1016/0360-3016 (95)02049-7

25. Bauchet L, Mathieu-Daudé H, Fabbro-Peray P, Rigau V, Fabbro M, Chinot $O$ et al. Oncological patterns of care and outcome for 952 patients with newly diagnosed glioblastoma in 2004. Neuro Oncol. 2010;12(7):725-35. http://dx.doi.org/10.1093/neuonc/noq030

26. Ash D, Barrett A, Hinks A, Squire C. Re-audit of radiotherapy waiting times 2003. Clin Oncol. (R Coll Radiol). 2004;16(6):387-94. http://dx. doi.org/10.1016/j.clon.2004.06.006

27. Klausen OG, Olofsson J, Rosengren B. [A long waiting time for radiotherapy: not acceptable for patients with neoplasms]. Tidsskr Nor Laegeforen. 1989;109(23):2324-5. Norwegian.

28. Denham J W, Hamilton CS, Joseph DJ. How should a waiting list for treatment be managed? Australas Radiol. 1992;36(3):274-5. http:// dx.doi.org/10.1111/j.1440-1673.1992.tb03170.x

29. Esco R, Palacios A, Pardo J, Biete A, Carceller JA, Veiras C et al. Infrastructure of radiotherapy in Spain: a minimal standard of radiotherapy resources. Int J Radiat Oncol Biol Phys. 2003;56(2):319-27. http://dx.doi.org/10.1016/S0360-3016(02)04580-7

30. Loureiro LVM, Pontes LB, Callegaro Filho D, Koch LO, Weltman E, Victor ES et al. Initial care and outcome of glioblastoma patients in 2 diverse health care scenarios in Brazil: does public versus private health care matter? Neuro Oncol. 2014;16(7):999-1005. http://dx.doi. org/10.1093/neuonc/not306 